\title{
'HUMANISING' STATELESSNESS THROUGH AN ARTISTIC APPROACH
}

\author{
MD MIZANUR RAHMAN*
}

In this article I critically examine an art-based approach to statelessness in institutional settings, to show how art can produce alternative insights on statelessness. Drawing from ethnographic observation, I show how an art-based approach tries to go beyond the predominant legalistic and political frames and representations of statelessness, but stay married to the same legal and political discourses. I found the art-based approaches observed do not subscribe to the idea that statelessness is only a legal anomaly and instead emphasise the creation of empathy for stateless individuals or groups. This humanises statelessness by showing their human vulnerability and creatively recognising their hope and agency. Regardless, artistic approaches can struggle to challenge the legalistic and political nature of the problem. It remains a question whether such approaches are appropriately promoting the views, perceptions and feelings of stateless persons themselves, as their participation in creating such art projects are minimal. As such, I argue for an 'ethnographic turn in art practices', which can ensure the participation of stateless people in the process of creating and demonstrating art. I believe this 'turn' could play a crucial role in the development of statelessness studies.

\section{TABLE OF CONTENTS}

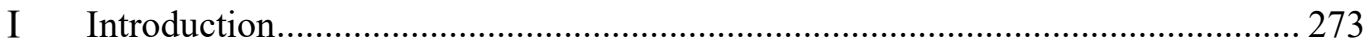

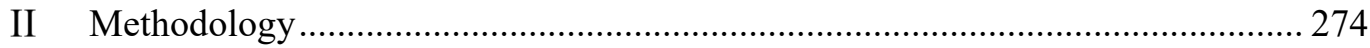

III The State of Statelessness Research: A Short Literature Review ......................... 277

A Defining Statelessness: Legal Framing and Representation.......................277

B Solving and Preventing Statelessness: A Focus on the 'Nation-State'

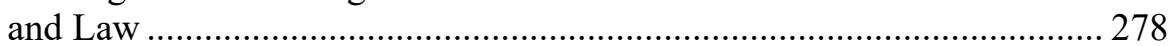

C Human Rights Perspective: Emphasising the Nation-State...................... 280

D Dominant Framing and Representations of Statelessness: Invisibility

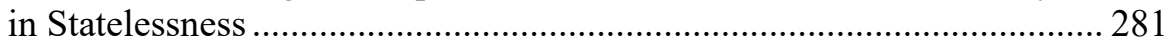

E An Artistic Approach to Statelessness..................................................... 282

IV 'Humanising' Statelessness through Generating Empathy .................................. 283

A Freeing Neha: An Art Experiment to Make Participants Feel

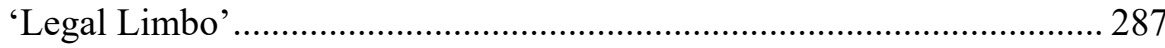

B Unseen and Untouchables: Searching for Hope with Hope ...................... 291

C How Do You Survive in a World That Does Not Recognise You?:

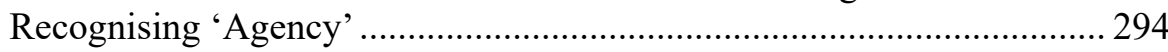

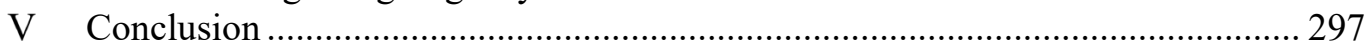

* Md Mizanur Rahman is an Assistant Professor of Anthropology at Jagannath University, Bangladesh. He holds an MA in Development Studies with track Governance of Migration and Diversity from the International Institute of Social Studies of Erasmus University Rotterdam, Netherlands. This article is an amended version of his Master's thesis. 


\section{INTRODUCTION}

We breathe, we bleed, we vibrate under the same sky as you. Our cries are whispers, our shouts are demands. Our love utterances are curses... We pulse at within and among these as you do. Yet, in your need to recognise, hypothesise, categorise, theorise, legalise, you forget to humanise. We are not stateless, and we are not merely a word. Within the act of listening lives the right to be heard. ${ }^{1}$

Statelessness is defined as the absence of a legal bond between the state and its individuals. This is evident in the 1954 Convention Relating to the Status of Stateless Persons ('1954 Convention'), which in art 1(1) defines a stateless person as, 'a person who is not considered as a national by any State under the operation of its law'. ${ }^{2}$ Article 15 of the 1948 Universal Declaration of Human Rights states that everybody has a right to nationality and nobody should arbitrarily be deprived of nationality. ${ }^{3}$ Those who do not have this fundamental right are considered stateless and may not enjoy the rights of citizenship offered by a state. Often, this legal bond with the state is intricately related to those rights associated with citizenship, meaning non-citizens are unable to enjoy the same domestic standard of rights that citizens do. ${ }^{4}$ This is no surprise when the existing legal and political discourses focus on the citizenship, nationality and legal aspects of statelessness. The legal discourse sees the issue as a 'legal anomaly' and the stateless are treated as 'non-persons' and 'legal ghosts'. 5 Such rhetoric confirms statelessness as nothing more than a formalised condition of insecurity and inferiority, makes stateless people invisible and places emphasis upon the sovereign power of states to differentiate between who might appear or disappear under the operation of its law; who does or does not belong. ${ }^{6}$ The 'ghostliness' of stateless persons portrayed in legal discourses dehumanises the issue by ignoring their feelings, perceptions and experiences. There is a growing sentiment among academics that legal and political approaches to ending statelessness are perhaps insufficient for such a complex problem. In this context, many believe that art can be an effective and alternative approach to presenting the complexity of statelessness to a wider audience. An artistic approach may, therefore, be an effective means of addressing the issue of statelessness and creating an environment that ensures justice for stateless persons through empathy, feeling and visualisation. ${ }^{7}$

1 Valerie Peay, 'Humanise' (Spoken Creative Writing Piece, World Conference on Statelessness and Inclusion (Institute on Statelessness and Inclusion, 26 June) 27:00 - 28:06 $<$ https://twitter.com/institute_si/status/1144573743424872448>.

2 See Convention Relating to the Status of Stateless Persons, opened for signature 28 September 1954, 360 UNTS 117 (entered into force 6 June 1960) art 1 ('1954 Convention').

3 Universal Declaration of Human Rights, GA Res 217A (III), UN GAOR, $3^{\text {rd }}$ sess, $183^{\text {rd }}$ plen mtg, UN Doc A/810 (10 December 1948) art 15.

4 The Rights of Non-Citizens (Report, UNHCR 2006) 5 $<$ https://www.ohchr.org/documents/publications/noncitizensen.pdf $>$.

5 Angela M Naimou, 'Statelessness and the Making of a Decolonial Aesthetics in US Literature' (DPhil Thesis, Cornell University 2009) 22.

6 ibid 23.

7 See, eg, Nicoletta Enria, 'Fostering Radical Empathy for Statelessness Using Arts', European Network on Statelessness (Blog Post, 24 January 2019) $<$ www.statelessness.eu/blog/fostering-radical-empathy-statelessness-using-arts>; Alex Danchev and Debbie Lisle, 'Introduction: Art, Politics, Purpose' (2009) 35(4) Review of International Studies 775; Lindsey N Kingston, 'Conceptualizing Statelessness as a Human Rights Challenge: Framing, Visual Representation, and (Partial) Issue Emergence’ (2019) 11(1) Journal of Human Rights Practice 52. 
In this article, I examine one such art-based approach employed by United Kingdom-based organisation Empathy and Risk, ${ }^{8}$ and its Netherlands-based partner organisation, Creative Court, ${ }^{9}$ where I worked as an intern for six months. This article is primarily based on my observations and analyses of the artworks exhibited and performed by those two organisations at the World Conference on Statelessness and Inclusion organised by the Institute of Statelessness and Inclusion ('ISI') that ran from 26-28 June 2019 in The Hague. ${ }^{10}$ I argue that the art-based approaches discussed in this paper intend to problematise discourses surrounding statelessness that are mostly limited to the legal and political fields. These artistic approaches try to break through this prevalence of legal rhetoric and metaphor. Through various artworks, they intend to humanise statelessness by bringing forward the agency, experiences, feelings, perceptions and hopes of stateless persons. In essence, an artistic approach aims to create empathy for the stateless. This paper demonstrates how art can 'humanise' the issue of statelessness through the generation of empathy for stateless persons that results from addressing their vulnerability, recognising their agency and engaging in their hopes. Artworks can successfully frame and represent statelessness in a different way, but often do not challenge dominant discourses or seek to change them. As will be discussed, I consider this inaction to be a major drawback of artistic approaches.

\section{MeTHODOLOGY}

This article addresses four questions. First, how have academics in legal, political and human rights fields framed and represented statelessness? Second, how does the art-based approach employed by Empathy and Risk and Creative Court frame and represent statelessness through various artworks? Third, how does an artbased approach produce a novel or different discourse on statelessness than that of law-based discourse? And finally, what are the drawbacks of such an approach? I adopted an ethnographical approach described by David Mosse to answer these questions, understand the ideas and practices of the aforementioned organisations and engage in their art projects and events on statelessness. ${ }^{11}$ In doing so, I positioned myself as an embedded researcher to explore the material and discursive practices of Empathy and Risk and Creative Court in everyday settings. Mosse stated that this type of insight

do[es] not arise from conventional anthropological research projects, but are the result of reflection on the experience of living and working as part of the interconnected expert world of international development. ${ }^{12}$

He categorises this type of research as 'insider ethnography' or 'autoethnography' - a form of research that values the reflexive capabilities of an observant participant as much as participant observers. ${ }^{13}$ His objective is to move from

8 See Empathy and Risk (Web Page) < http://www.empathyandrisk.com/>.

9 See Creative Court (Web Page) $<$ https://www.creativecourt.org/>.

10 For details, see 'World Conference on Statelessness', Institute on Statelessness and Inclusion (Web Page, 2019) <https://www.institutesi.org/raising-awareness/world-conference-onstatelessness $>$.

11 David Mosse (ed), Adventures in Aidland: The Anthropology of Professionals in International Development (Berghan 2011).

12 ibid vii.

13 ibid. 
'planning knowledge out of ethnography' towards making 'ethnography out of planned knowledge'. 14

In this type of research, insights come from combining the experience of insider participation with the detachment of an outsider. ${ }^{15}$ My positions both as an intern of Creative Court and as an observer meet this standard; I both observed and partook in activities related to knowledge production processes on statelessness and artistic practices. Consistent challenges in the duality of my positions were found in my pre-existing biases and assumptions regarding the issue of statelessness. On this challenge, Kim England argued that it is not easy for the researcher to take the 'personal' out of the equation when it comes to the 'professional', because fieldwork itself is personal. ${ }^{16}$ For instance, I initially assumed that operating within the nation-state framework without challenging it was not going to help eradicate statelessness. However, Rabiaa Benlahbib, director of Creative Court, maintained a position that the organisation was not going to make things political. It was hard for me to understand such a position as, for me, art is inherently political, regardless of whether one wants it to be or not. So, when we engaged in discussion, I would pose the idea of challenging the nation-state, and she would motivate me to look at the influence and significance of artistic approaches to statelessness. Gradually, both our opinions took on characteristics of the other's argument. She would say, 'I want you to get yourself out from under your academic ideas and think like a human'. ${ }^{17}$ I would then argue that 'as a human being, I cannot alienate my background or the waves of thought I have developed over the years'. ${ }^{18}$ Ghislaine Gallenga illustrated these delicate challenges that derive from doing ethnography in the workplace. She states, "the main drawbacks are that the ethnographer will only be assigned a subordinate role and will be constantly caught between her position as an employee and her status as a researcher'. ${ }^{19}$ In this context, 'interpretive reflexivity' was important for me to deal with those challenges. According to Paul Lichterman,

[i]f we ethnographers want to make our explanatory claims more transparent and disputable by readers, then we need to show readers how we came up with our interpretations, how we made mistakes and lucky guesses along the way to capturing other people's meanings. That is what interpretive reflexivity discloses. ${ }^{20}$

I found this insight useful when writing my field notes and subsequently analysing my notes in a more reflective way.

My position as an intern also allowed me to observe and participate in Creative Court's artistic approach to conceptualising, framing and representing statelessness. I have used observation for this ethnographic research to collect the primary materials used for this article, along with my everyday conversations and idea exchanges with members of Creative Court. I did not conduct any structured

\footnotetext{
14 ibid viii.

15 ibid.

16 Kim England, 'Getting Personal: Reflexivity, Positionality, and Feminist Research' (1994) 46(1) The Professional Geographer 85.

17 Informal Conversation with Rabiaa Benlahbib, Director, Creative Court (Mizanur Rahman, Creative Court 15 March 2019).

18 ibid

19 Ghislaine Gallenga, 'Elements of Reflexive Anthropology in Three Fieldwork Studies of the Workplace' (2013) 2(2) Journal of Business Anthropology 187, 189.

20 Paul Lichterman, 'Interpretive Reflexivity in Ethnography' (2015) 18(1) Ethnography 35, 38. (emphasis in original).
} 
or semi-structured interviews, as I wanted to experience the artistic process of the organisation and events from a 'natural' setting. I felt that interviews could have manipulated my experience as an observant participant. I was engaged in informal discussions with the artists, participants and other members of Creative Court as a team member. Throughout the observation process, I was also a participant. This meant the observed were aware of my presence as a researcher as I participated in the process. This strategy was labelled as 'candid participance' in observational studies. ${ }^{21}$ Being an intern and a researcher at the same time allowed me to 'explore what people actually do, and not just what they say they do'. ${ }^{22}$

As an intern of Creative Court, I had access to the events that Creative Court organised and participated in. This included the 2019 World Conference on Statelessness and Inclusion organised by the Institute on Statelessness and Inclusion ('ISI'). Creative Court participated in that Conference with their partner organisation, Empathy and Risk. They participated through the presentation of their artworks, such as visual photography, video installation, audio installation, poetry, live performances, art experiments and discussion sessions. This conference was the focus of my observation and research; most of my observational data derived from this conference setting. As part of the Conference I attended a series of discussions and exhibits with artists. Observing and participating in those events and discussions helped me to understand how statelessness is currently framed and the concepts behind those frames. Besides the Conference, Creative Court was also working on a new artistic project to illustrate the connection and resilience of stateless people. As an active participant in this artistic research project, I have observed and analysed the types of knowledge and ideas that are being employed to conceptualise and represent statelessness. Data was recorded in a diary with written notes and observations, photos of the artworks and evening elaborations upon the observation data, all of which were analysed later.

Insights from the anthropology of art were useful in understanding and examining the role of artistic approaches in the field of statelessness. For example, Alfred Gell's concept of the 'anthropology of art' emphasised the importance of the social context of art production, circulation and reception, rather than the evaluation of particular works of art. ${ }^{23}$ By observing Creative Court's particular artistic approach, this research also goes beyond individual pieces of artwork, and instead concentrates on the ideas, frames and concepts that art-based approaches deliver upon statelessness. Similarly, Austin Harrington argued that the anthropology of art should show

how aesthetic frames of perception enter into textual aspects of metaphor, analogy and vignette, into sensuous media of data analysis such as visual images and lifestory narratives; and into conceptions of theatrical qualities in social action. ${ }^{24}$

Thus, the anthropology of art is not only concerned with the materiality of artworks, but also retains a focus on the knowledge art produces when people

21 Zina O'Leary, The Essential Guide to Doing Your Research Project (Sage Publishing 2009) 253.

22 ibid 254.

23 Alfred Gell, Art and Agency: An Anthropological Theory (Oxford University Publishing 1998) 3.

24 Austin Harrington, Art and Social Theory: Sociological Argument in Aesthetics (Wiley 2004) 6. 
embrace and engage with it. Throughout this research, I investigated the artworks, metaphors, performances related to statelessness informed by such insights.

Finally, I followed the grounded theory approach to understand my observation notes, transcriptions of discussion sessions, informal discussions and conversations. I decided not to employ a pre-determined theoretical framework to look at my data. Rather, I wanted to see what themes and sub-themes came from my observations and how these fit or contradicted existing discourses. Barney Glaser and Anselm Strauss considered grounded theory to address 'how the discovery of theory from data systematically obtained and analysed in social research-can be furthered', rather than the rigorous analysis conducted upon the data in the theories of other sociological studies. ${ }^{25}$ Likewise, the main concepts in this article — humanisation, empathy, hope and agency - came from my observation of the artworks, narrative and concepts employed by Creative Court and Empathy and Risk, as well as through my informal discussions and conversations with the artists and officials of both organisations.

\section{The State of Statelessness Research: A SHORT Literature ReVIEW}

Statelessness is still considered an understudied and neglected issue. ${ }^{26}$ Nevertheless, academics and organisations — such as the United Nations High Commissioner for Refugees ('UNHCR'), European Network on Statelessness and ISI - publish a significant amount of research on statelessness. It is impossible to present the plethora of research and literature in these short paragraphs, but I intend to present the main thematic areas from existing pieces of literature. I have divided the literature into three broad thematic areas to present how statelessness is dominantly framed and represented, namely, defining statelessness, solving or preventing statelessness and critiques of human rights and nation-state frameworks. This also answers my first research question. Later, I discuss the importance of using art and artistic approaches to show what place art has in the field of statelessness.

\section{A Defining Statelessness: Legal Framing and Representation}

Theoretically speaking, defining statelessness from a legal perspective is straightforward since, as explained above, the 1954 Convention outlines the definition of stateless persons. However, it is a complex and multifaceted issue and can arise from many different contexts and circumstances. ${ }^{27}$ Common representations of statelessness emphasise that a lack of a nationality creates a

25 Barney Glaser and Anselm L Strauss, The Discovery of Grounded Theory: Strategies for Qualitative Research (Aldine Transaction 1967) 1.

26 Alice Edwards and Laura Van Waas, 'Statelessness' in Elena Fiddian-Qasmiyeh et al (eds), The Oxford Handbook of Refugee and Forced Migration Studies (Oxford University Publishing 2014) 290, 298.

27 See Tendayi Bloom, Katherine Tonkiss and Phillip Cole, 'Introduction: Providing a Framework for Understanding Statelessness' in Tendayi Bloom, Katherine Tonkiss \& Phillip Cole (eds), Understanding Statelessness (Routledge 2017). See also Handbook on Statelessness in the OSCE Area: International Standards and Good Practices (Report, Organization for Security and Co-Operation in Europe 28 February 2017) 9 $<$ https://www.osce.org/files/f/documents/5/1/302201.pdf $>$; Institute on Statelessness and Inclusion, The World's Stateless (Wolf Legal 2014). 
structural and legal imbalance for those it effects. ${ }^{28}$ Some have also argued that the term statelessness is a slippery one; it is perceived by some as a narrow, technical, legal concept, yet embraced by others as a broad descriptor for a lack of belonging or situation of rightlessness. ${ }^{29}$ Generally speaking, defining statelessness is about the absence of nationality. Thus, narratives of statelessness often define statelessness as a legal anomaly of non-existent legal bonds between the people and state. In doing so, predominant legal narratives and discourses do not give attention to the perception, feelings or agency of stateless persons - they become a number. But people do not connect with numbers, nor do they feel empathy for statistics.

\section{B Solving and Preventing Statelessness: A Focus on the 'Nation-State' and}

\section{Law}

The second stream of literature focuses on those issues associated with finding solutions and resolving statelessness. The \#IBelong Campaign to End Statelessness launched by UNHCR in November 2014 renewed optimism for the prevention of statelessness, and was endorsed by the United Nations General Assembly in the same year. ${ }^{30}$ Much of the literature on solving statelessness identifies the nation-state's role as key, regardless of the different strategies that need to be adopted or areas to be improved. Some authors stress the need for the proper and full implementation of the 1954 Convention and 1961 Convention on the Reduction of Statelessness, ${ }^{31}$ while others point to the importance of human rights conventions to deal with statelessness. ${ }^{32}$ Others still have a different approach to resolving statelessness based on how they conceptualise statelessness in the first place. For example, Radha Govil suggests that implementing the 2015 UN Sustainable Development Goals can help reduce statelessness, as statelessness is a core development issue, not just a humanitarian and human rights issue. ${ }^{33}$

28 See, eg, See Lindsey N Kingston, 'Worthy of Rights: Statelessness as a Cause and Symptom of Marginalisation' in Tendayi Bloom, Katherine Tonkiss and Phillip Cole (eds), Understanding Statelessness (Routledge 2017) 17; Caia Vlieks, 'Contexts of Statelessness: The Concepts of "Statelessness in Situ" and "Statelessness in the Migratory Context" in Tendayi Bloom, Katherine Tonkiss and Phillip Cole (eds), Understanding Statelessness (Routledge 2017) 35.

29 Amal de Chikera and Laura van Waas, 'Unpacking Statelessness' in Tendayi Bloom, Katherine Tonkiss and Phillip Cole (eds), Understanding Statelessness (Routledge 2017) 53.

30 Global Action Plan to End Statelessness 2014-2024 (Report, UNHCR 2014) $<$ https://www.unhcr.org/en-au/protection/statelessness/54621bf49/global-action-plan-endstatelessness-2014-2024.html> ('UNHCR Global Action Plan').

31 See Convention on the Reduction of Statelessness, opened for signature 30 August 1961, 989 UNTS 175 (entered into force 13 December 1975). See also Edwards and van Waas (n 26); Amal de Chikera and Joanna Whiteman, 'Addressing Statelessness through the Rights to Equality and Non-Discrimination' in Laura Van Waas and Melanie J Khanna (eds), Solving Statelessness (Wolf Legal 2017) 99; Türk Volker, 'Introduction' in Laura Van Waas \& Melanie J Khanna (eds), Solving Statelessness (Wolf Legal 2016) 1.

32 Melanie J Khanna and Peggy Brett, 'Making Effective Use of UN Human Rights Mechanisms to Solve Statelessness' in Laura Van Waas and Melanie J Khanna (eds), Solving Statelessness (Wolf Legal 2016) 13.

33 Radha Govil, 'The Sustainable Development Goals and Solutions to Statelessness' in Laura Van Waas and Melanie J Khanna (eds), Solving Statelessness (Wolf Legal 2016) 49, citing Transforming Our World: The 2030 Agenda for Sustainable Development, UN Doc A/RES/70/1 (21 October 2015) 21. 
Tamás Molnár has expressed a similar view. ${ }^{34}$ From the literature concerned with solving statelessness, whether by implementing human rights conventions properly or by eradicating discriminatory nationality laws based on gender, race, ethnicity or religion, ${ }^{35}$ it is undeniable that the nation-state is a point of focus. Nevertheless, some literature also discusses how international and regional communities can create pressure on states or mobilise the rights of stateless persons to influence nation-states. 36

In contrast, other literature focuses on the setbacks involved in resolving statelessness. For instance, Zahra Al Barazi and Jason Tucker have discussed how the absence of a common language or consistent frameworks for accessing citizenship — in avoiding statelessness — hinders the efficacy of reducing statelessness in a region such as the Middle East. ${ }^{37}$ Tendayi Bloom problematises the idea that stateless persons ought to find remedies for their situation through the citizenship framework of the recognised nation-state, although the author does not deny the importance of citizenship in the current nation-state-based world for accessing human rights. ${ }^{38}$ Similarly, Kelly Staples also focuses on the discriminatory way states treat certain groups in the provision of citizenship rights and their inability to ensure basic universality in human status. ${ }^{39}$ This last point remains a setback to UNHCR's aims of ending statelessness through birth registration, documentation and non-discrimination, reflected in each case in the politics of recognition. ${ }^{40}$

34 Tamás Molnár, 'A Fresh Examination of Facilitated Naturalization as a Solution for Stateless People' in Laura Van Waas and Melanie J Khanna (eds), Solving Statelessness (Wolf Legal 2016) 230 .

35 Laura van Waas, Zahra Albarazi and Deirdre Brennan, 'Gender Discrimination in Nationality Laws: Human Rights Pathways to Gender Neutrality' in Niamh Reilly (ed), International Human Rights of Women (Springer 2019) 193, 207; Neda Shaheen, 'Discriminatory Nationality Laws Must Be Eliminated in Order to Eradicate Statelessness' (2018) 11(2) DePaul Journal for Social Justice 1; Ronan Lee, 'Myanmar's Citizenship Law as State Crime' (2019) 8(2) State Crime Journal 241.

36 Bronwen Manby, Ayalew Getachew Assefa and Julia Sloth-Nielsen, 'The Right to a Nationality in Africa: New Norms and New Commitments' in Laura Van Waas and Melanie J Khanna (eds), Solving Statelessness (Wolf Legal 2016) 261; Laura van Waas, Katja Swider and Giulia Bittoni, 'The Evolving Role of the European Union in Addressing Statelessness' in Laura Van Waas and Melanie J Khanna (eds), Solving Statelessness (Wolf Legal 2017) 375.

37 Zahra Al Barazi and Jason Tucker, 'Challenging the Disunity of Statelessness in the Middle East and North Africa' in Tendayi Bloom, Katherine Tonkiss and Phillip Cole (eds), Understanding Statelessness (Routledge 2017) 87.

38 Tandayi Bloom, 'Members of Colonised Groups, Statelessness and the Right to Have Rights' in Tendayi Bloom, Katherine Tonkiss and Phillip Cole (eds), Understanding Statelessness (Routledge 2017) 153.

39 Kelly Staples, 'Recognition, Nationality, and Statelessness: State-Based Challenges for UNHCR's Plan to End Statelessness' in Tendayi Bloom, Katherine Tonkiss and Phillip Cole (eds), Understanding Statelessness (Routledge 2017) 173.

40 See, eg, UNHCR Global Action Plan (n 30). See also Ending Statelessness within 10 Years (Report, UNHCR 2010) $<$ https://www.unhcr.org/protection/statelessness/546217229/special-report-endingstatelessness-10-years.html>; I Am Here, I Belong: The Urgent Need to End Childhood Statelessness (Report, UNHCR 2015) < https://www.unhcr.org/ibelong/the-urgent-need-toend-childhood-statelessness/>. 


\section{Human Rights Perspective: Emphasising the Nation-State}

Hannah Arendt, in her famous book The Origins of Totalitarianism, coined the phrase 'the right to have rights' to describe the situation of stateless persons. ${ }^{41}$ Careful analysis of her position on statelessness shows that, in order to have or enjoy other human rights, being merely human is not enough. Rather, one must have a right of nationality first or be a part of a political community. ${ }^{42}$ Thus, Arendt rejected the normative claims of universal rights. ${ }^{43}$ Arendt concludes that what stateless people lack is the fundamental 'right to have rights'; the political and legal recognition that would come with being a member of a certain political community. 44

Brad Blitz and Miguel Otero-Iglesias summarised this position on statelessness:

For Arendt, statelessness illustrated a situation of 'rightlessness' which involved three distinct losses: of a home, as a result of being thrust into exile; of government protection, as a result of denaturalisation or the severing of the bond between the state and the individual; and of 'a place in the world' where the individual could belong, be heard and express his or her opinions. Statelessness therefore entailed the loss of the right to have rights. ${ }^{45}$

The presence of stateless people led Arendt to claim that human rights, supposedly universal, have no meaning unless they can be anchored to an effective source of protection and, for her, the only option is the state. ${ }^{46}$ Giorgio Agamben also rejected the idea that human rights are guaranteed to human beings just because they are human. ${ }^{47}$ Unlike Arendt, said John Lechte and Saul Newman,

Agamben believes that $z o \bar{e}$ ['bare life'] is appropriated by the mechanisms of sovereign political power even as the excluded and abandoned entity, caught, as he puts it, in the relation of the ban. In other words, to be subject to the ban or to be consigned to the status of homo sacer - the 'sacred' man who may be killed but not sacrificed - is to be placed on a terrain of radical freedom (as in the State of Nature), but, on the contrary, to be abandoned by the law and removed from its protections, and thus to be subject to lawless sovereign violence. ${ }^{48}$

This situation of abandonment by law or the sovereign 'ban' applies to the situation of stateless people. ${ }^{49}$ Both Arendt and Agamben were critical of the sovereignty of the state, but at the same time, they did not offer us any other way to conceptualise or define statelessness. Notably, Arendt's critical stance of

41 Hannah Arendt, The Origins of Totalitarianism (new edn, Harcourt Brace Jovanovich, 1976) 302 .

42 ibid.

43 See Brad K Blitz and Miguel Otero-Iglesias, 'Stateless by Any Other Name: Refused AsylumSeekers in the United Kingdom' (2011) 37(4) Journal of Ethnic and Migration Studies 657, 658-60.

44 John Lechte and Saul Newman, 'Agamben, Arendt and Human Rights: Bearing Witness to the Human' (2012) 15(4) European Journal of Social Theory 522, 523.

45 Blitz and Otero-Iglesias (n 43) 659 (emphasis in original).

46 See Brad K Blitz, 'The State and the Stateless: The Legacy of Hannah Arendt Reconsidered' in Tendayi Bloom, Katherine Tonkiss and Phillip Cole (eds), Understanding Statelessness (Routledge 2017) 70.

47 See Giorgio Agamben, Homo Sacer: Sovereign Power and Bare Life (Stanford University Press 1998).

48 Lechte and Newman (n 44) 524 (emphasis in original), discussing Agamben (n 47) 110.

49 ibid 525. 
international law seems to stumble when she considers states for the protection of the stateless people, when they are responsible for having made them stateless in the first place.

\section{Dominant Framing and Representations of Statelessness: Invisibility in}

\section{Statelessness}

The kinds of literature discussed above are important to the analysis of statelessness, but they suffer from a singular and linear way of seeing the subject. This literature defines, categorises and theorises statelessness as centred on the legal and nation-state framework. The framing of the issue relates to 'nationality law', 'international law' and 'citizenship statuses'. In this respect, stateless people are merely visible through the lens of their legal status, they are represented as 'rightless' and 'citizens of nowhere' ${ }^{50}$ Meanwhile, their experiences mostly remain invisible. Phillip Cole criticised such positions. He stated 'finding a solution to statelessness is about asking radical questions about the international political order'. ${ }^{51}$ Cole also argued that

the theoretical basis for discourses of membership and mobility must be challenged and transformed. What membership means has to be fought over, rather than taken as our starting point. The fight is not just for membership, but also for its meaning. And what we realise is that its meaning will be determined not by the theorists and policy makers, but also by the stateless themselves acting out these ideas in their everyday lives. What is needed is dialectic between theory and lived experience. ${ }^{52}$

This position is very similar to the anthropological criticism of 'sedentary metaphysics', which sees peoples and cultures categorised into national soils and the family of nations. ${ }^{53}$ Anthropologists taking up a postmodern view strongly criticise the 'territorialisation' of people and culture within existing national boundaries. ${ }^{54}$ Lisa Malkki questions the idea of territorialisation and brings forward the idea of 'deterritorialisation', which focuses instead on issues such as migration experiences, the memory of dispossession and displacement and lived responses to being uprooted. ${ }^{55}$ However, these critical theories appear to be contra to the dominant discourse; most political, legal and policy experts see statelessness as a problem concerning citizenship and nationality. In doing so, they assume that nationality is a natural concept and every person must have one. They

50 For an elaboration on this term see, eg, Citizens of Nowhere: Solutions for the Stateless in the US (Report, UNHCR and Open Society Justice Initiative 2012).

51 Phillip Cole, 'Insider Theory and the Construction of Statelessness' in Tendayi Bloom, Katherine Tonkiss and Phillip Cole (eds), Understanding Statelessness (Routledge 2017) 255, 258.

52 ibid 264 (emphasis in original).

53 Lisa Malkki, 'National Geographic: The Rooting of Peoples and the Territorialization of National Identity among Scholars and Refugees' (1992) 7(1) Cultural Anthropology 24.

54 See, eg, Arjun Appadurai, 'Disjuncture and Difference in the Global Cultural Economy' (1990) 7(2-3) Theory, Culture \& Society 295; James Clifford, The Predicament of Culture: Twentieth-Century Ethnography, Literature, and Art (Harvard University Press 1988); Renato Rosaldo, Culture and Truth: The Remaking of Social Analysis (Beacon Press 1989); Ulf Hannerz, 'The World in Creolisation' (1987) 57(4) Africa: Journal of the International African Institute 546.

55 Lisa Malkki (n 53), cited in Dawn Chatty, 'Anthropology and Forced Migration' in Elena Fiddian-Qasmiyeh et al (eds), The Oxford Handbook of Refugee and Forced Migration Studies (Oxford University Press 2014) 74, 75. 
conceptualise statelessness from a sedentary view, which undermines and ignores stateless people's perceptions and views.

\section{E An Artistic Approach to Statelessness}

It is well recognised in academia that art is an important tool for challenging existing knowledge and creating new knowledge(s), although it is conceptually less focused. Alex Danchev and Debbie Lisle emphasised the importance of art in society. ${ }^{56}$ They wrote,

art matters, ethically and politically; affectively and intellectually. It is another way of apprehending the world. It has consequences. Not only does it make us feel, or feel differently, it also makes us think, and think again. ${ }^{57}$

They call for a critical understanding and observation of art; 'there must be a politics in our observation'. ${ }^{58}$ On this, Harrington states, '[ $\left.\mathrm{t}\right]$ he knowledge art can convey about society is no substitute for the methodical knowledge of social science; but neither is it inferior or subordinate to the latter'. 59

Art and artistic approaches have gained particular acceptance and importance in the context of human rights issues. The European Union Agency for Fundamental Rights ('FRA') states:

Much of the human rights agenda is directed at bridging attitudinal disparities, such as prejudices based on race, religion, gender, age, nationality, culture and identity. Art can help to overcome those barriers, by bringing a counter-discourse, contesting privileged narratives and perspectives. ${ }^{60}$

FRA also recommended strengthening the connection between art and human rights as it can reinforce the message of the latter. In this regard, the report stated:

The professional field of human rights can learn a lot from the field of arts. Emotions commonly drive decisions; yet, modern societies (wrongly) believe to be driven by rational thought and intellect. We do not only think, therefore we are, but we also feel, therefore we are. Indeed, perceptions (including love, hate, hope, forgiveness, horror and empathy) are more powerful than facts, especially when society's acceptance of facts is rapidly fracturing. ... Art can transcend barriers, such as politics and language. ${ }^{61}$

The artistic approach to addressing statelessness employed by Creative Court and its partner organisation is also about showing stateless peoples' conditions, perceptions and feelings. Nicoletta Enria suggests radical empathy for statelessness could be fostered through the utilisation of art. ${ }^{62}$ According to Enria, in the case of statelessness, radical empathy would make audiences feel what it is like to be a stateless person. She states,

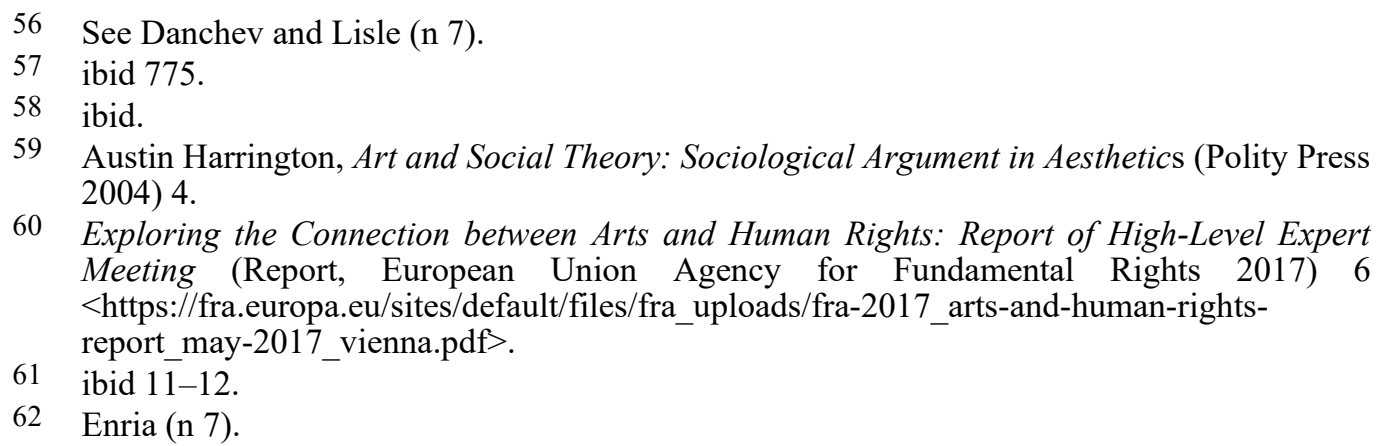


art has always been effective at speaking out against injustice. Indeed, historically, art has been a powerful resource for oppressed communities themselves to tell their stories and mark their existence, by way of forcing people to listen, stop, reflect and put themselves in their shoes. As such art can be an extremely effective way to foster radical empathy. ${ }^{63}$

Similarly, Lindsey N Kingston places emphasis on visual representation to bring the issue of statelessness to wider audiences. ${ }^{64}$

However, none of the reports or authors discussed investigate or ask how art comes into being and what kind of ideas, knowledge and concepts are used to develop an artistic approach. As Rika Allen argues, artistic representations often reproduce knowledge that already exists. She argues that the knowledge artwork brings forward cannot be neutral when the artist's ideology plays such a crucial role; the art is determined by the artist's knowledge. ${ }^{65}$ Allen states, 'the [artist's] gaze is influenced by what is known, knowledge is also influenced by how one sees the world'. ${ }^{66}$ In the context of my research, I investigated these issues by participating and observing the art-based approaches employed by Creative Court and its partner on statelessness. I set out to understand the ways art frames and represents statelessness, the strategies it suggests and the kind of knowledge it brings forward from a critical standpoint.

\section{IV 'HumANISING' STATELESSNESS THROUGH GENERATING EMPATHY}

In this Part, I analyse the major themes that came from my observation. I show how an artistic approach to statelessness strongly advocates communicating with wider audiences by showing the human aspects of statelessness. The main objective of this Part is to present how art 'humanises' statelessness and how it is different from the dominant discourses already discussed, which in turn answers my second and third research question simultaneously. Statelessness is most often framed and represented as a 'legal anomaly' 67 and thus 'exists in a vacuum'. ${ }^{68}$ Creative Court and its partner Empathy and Risk wanted to go beyond this lens with their artwork. Both organisations shared a common idea: rules and laws insufficiently address problems of stateless people - they do not show the human side of the problem and fail to 'move' society. Building on this idea, they came up with an art programme entitled 'Cancelled Art', ${ }^{69}$ which was designed to unveil these human conditions of statelessness at the World Conference on Statelessness and Inclusion. David Cottrell, founder of Empathy and Risk explained it in the opening session of the conference. He said,

63 ibid.

64 Kingston, 'Conceptualizing Statelessness' (n 7) 52.

65 Rika Allen, 'The Anthropology of Art and the Art of Anthropology - A Complex Relationship' (Masters Thesis, University of Stellenbosch 2008).

66 ibid 6.

67 For example see Alice Edwards and Carla Ferstman, Human Security and Non-Citizens: Law, Policy and International Affairs (Cambridge University Press 2010); Mark Manly and Laura van Waas, 'The State of Statelessness Research' (2014) 19(1-2) Tilburg Law Review 3.

68 Kingston, 'Conceptualizing Statelessness' (n 7) 54.

69 'Cancelled Art Programme', Creative Court (Web Page, 2019) $<$ https://www.creativecourt.org/index.php/portfolio/cancelled/>; 'Cancelled Arts Programme', Empathy and Risk (Web Page, 2019) <http://www.empathyandrisk.com/2019/06/26/cancelled-arts-programme/>. 
The Cancelled Art programme has an unusual name. It occurs to us that something has to exist first before it is cancelled, and somehow they are denied their agency and access. We are thinking to understand the construction around it; it is not something just about legal or illegal. We want to combine the pluralism of activities through our programme. Through new artworks, archives, poetry, filmmaking, installation art, performances we would try to remove the boundaries between systems and individual, and we will show the human aspects of statelessness. ${ }^{70}$

During my internship, Rabiaa almost told me the same. She said:

In the conference, the idea is to translate the diverse experiences and conditions of stateless people in artistic ways so that the wider audience feels empathy and connection with the stateless people because the legal approach cannot do much in this case of statelessness, which is apparent from the growing pile of stateless people all around the world. We will try to translate these ideas which will be an alternative way to experience the realities around statelessness. ${ }^{71}$

When I asked her what she means by 'alternative way', she replied with a smile, 'a human way'. 72

Thus, the main theme from my observation was a 'humanisation' of statelessness. Artworks on statelessness have tried to frame and represent statelessness in a variety of ways. This contrasts legalistic and state-centred approaches, the strict foci of which can dehumanise stateless persons. The message should be that stateless people are human beings, who have lost their homes, occupations, languages and all the familiarity of life. The art-based approach proposes to see them as human beings and, most importantly, suggests listening to their stories to get a sense of their feelings of frustration, fear, denial, resistance and agency, as well as their overall existence as stateless persons. Just like Ralph Ya, an artist associated with Empathy and Risk told me: 'we are here to humanise the issue of statelessness. It's about humanising this very legal thing by establishing human connections between stateless people and the rest of us' ${ }^{73}$ This motive to humanise statelessness through an artistic approach can also be found in the work of Mark Manly and Laura van Waas:

Although statelessness is undeniably a legal anomaly, at its heart, it is also a human condition. It affects people - often in devastating ways. Not only does it have an impact on their legal status and ability to exercise rights, but it also affects the way they are perceived and how they perceive themselves. ${ }^{74}$

How do you then humanise the issue of statelessness? Or, how do you establish a human connection with people who have never experienced statelessness? The major concept I heard over and over again during my internship was empathy. David Cotterell, Rabiaa, other team members and artists all mentioned using art to create empathy for the stateless person, so that policymakers, academics, experts and civil society would understand what it is like to be a stateless person, and how it feels when the world around you does not recognise you. Every artwork and performance exhibited or performed in the conference venue had one common

70 David Cotterrell, Co-founder of Empathy and Risk, 'Cancelled Art' (Speech, World Conference on Statelessness and Inclusion, 26 June 2019) (copy on hand with author).

71 Informal Conversation with Rabiaa Benlahbib, Director, Creative Court (Mizanur Rahman, Creative Court 2 March 2019).

72 ibid.

73 Informal conversation with Ralph Ya, Artist, Empathy and Risk (Mizanur Rahman, 23 June 2019).

74 Manly and van Waas (n 67) 5. 
objective apart from their specific messages - create empathy among the participants. How do we define empathy? Rabiaa once told me, 'empathy means feeling like someone. When you can feel like what a stateless person feels, that will create empathy'. 75

Empathy as a guiding concept for creating feeling and emotion for others is well illustrated and supported by the existing literature. For instance, Faith Valente argued:

Empathetic understanding is both an important determinant of how well we communicate with each other as well as a personal characteristic that facilitates our ability to persuade other people to accept an idea, feel a particular way, or pursue a certain course of action. ${ }^{76}$

Thus, empathy can create cumulative responses and processes for further action. As Ralph Adolphs mentions, each response from an empathetic attribution is likely to start other empathetic processes and responses. ${ }^{77}$ As a practice, empathy defines our sociality — it is intricately connected with 'shared emotions' and 'social identity'. ${ }^{78}$ Therefore, empathy can be a useful method for learning and reaching out to other people. For instance, Adil Kutlu and Lokman Coskun discussed how empathy enabled students to get engaged in, and obtain, the desired outcome in school. They argued:

Empathy teaches the teachers, parents, and the other people the way how to feel the other people feel in the same fashion. Because, it is not possible to make people have the same feelings and the same experiences in their lives, but it is possible to put yourself in other's shoes to feel what they feel. ${ }^{79}$

Creative Court and Empathy and Risk wanted to undertake a similar task; create empathy for stateless people among the participants of the conference who would later do their best to erase statelessness.

Throughout the conference, several artworks and performances succeeded in creating empathy within the participants, including me. For instance, on the first day of the conference, Rabiaa asked me to write down 'the absent' and put it on an empty chair (Figure 1). I then heard that there was a plan to keep a chair empty for every staged session. I realised that this symbolic gesture was to recognise stateless people - this conference was about them, but none of them could be here without documents to travel. I truly felt the message conveyed. It was a symbol of silence illustrating the absence of stateless people and their lack of legal identity. This simple yet powerful gesture of artistic intervention was presenting stateless people, generating feelings for them in myself and the participants. As one participant said, 'it is funny that we are here in a conference on statelessness,

75 Informal Conversation with Rabiaa Benlahbib, Director, Creative Court (Mizanur Rahman, Creative Court 4 April 2019).

76 Faith Valente, 'Empathy and Communication: A Model of Empathy Development' (2016) 3(1) Journal of New Media and Mass Communication 1.

77 Ralph Adolphs, 'The Social Brain: Neural Basis of Social Knowledge' [2009] 60 Annual Review of Psychology 693, 716.

78 Thomas Szanto and Joel Krueger, 'Introduction: Empathy, Shared Emotions and Social Identity’ (2019) 38(11) Topoi 153.

79 Adil Kutlu and Lokman Coskun, 'The Role of Empathy in the Learning Process and Its Fruitful Outcomes: A Comparative Study’ (2014) 4(2) Journal of Educational Research 203. 
but the stateless people themselves are not here, because they do not have a passport'. 80

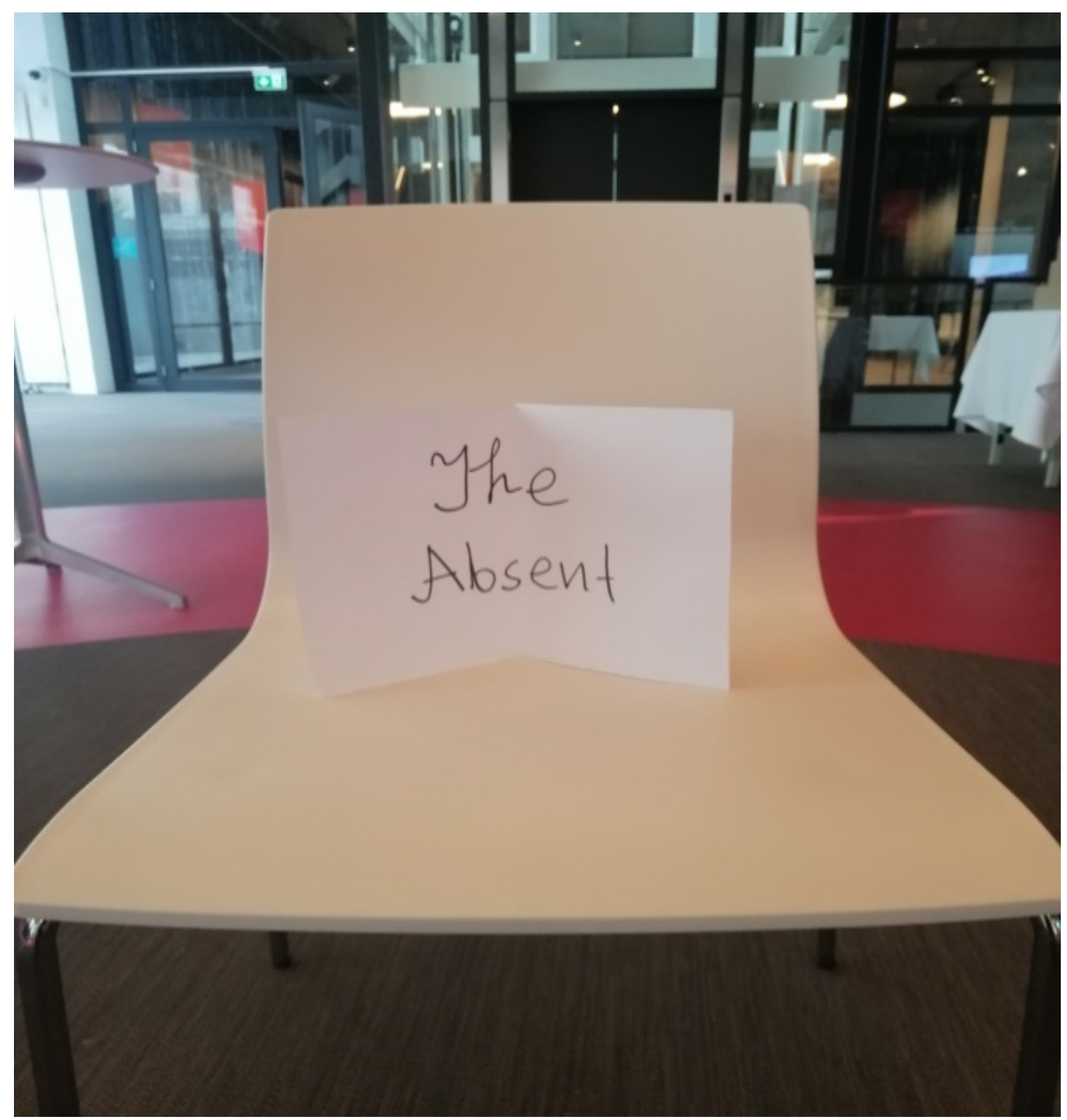

Figure 1: An empty chair for the stateless people, the absent people. ${ }^{81}$

As the conference proceeded, I observed various participant reactions to artworks and kept an account of my own feelings towards any particular piece. In the following Part, I move to present and analyse various artworks and experiments that tried to present different human aspects of statelessness. Primarily, they sought to convey vulnerability, hope and agency.

80 Observation of an anonymous participant (Mizanur Rahman, World Conference on Statelessness and Inclusion, 26 June 2019).

81 Mizanur Rahman, An Empty Chair for the Stateless People, the Absent People (Photo, World Conference on Statelessness and Inclusion 26-28 June 2019). 
A Freeing Neha: An Art Experiment to Make Participants Feel 'Legal

Limbo'

Statelessness has been described as a 'legal limbo'. ${ }^{82}$ Nonetheless, it is often not entirely clear what that means. David Cottrell told me:

People do not easily understand what is meant by 'legal limbo'. So, they do not feel connected with the situation. We want to communicate with a wider audience through art approaches to establish that human connection between the stateless and the people who never knew what it feels like to be in a limbo situation. ${ }^{83}$

Creative Court and Empathy and Risk came up with the idea of a 'bubble' as a metaphor to visualise and translate legal limbo to a wider audience. The image of a girl, who they named Neha, was placed with a mirror for her face inside a clear and transparent bubble with no exit (Figure 2). To look at Neha was to see one's self in the reflection. Ralph Ya explained the concept to me: 'it is because statelessness is constructed, anybody can be stateless in any time, and anybody can find themself in the place of Neha'. ${ }^{84}$ I tried to imagine myself in the same place as Neha, and it shocked me to find I could not imagine the same situation for myself. Who could?

Neha is trapped inside a bubble, she cannot go outside, go to school or play. To free her, Ralph Ya announced, we needed 46 Nepali passports. People who want to help Neha had to pretend that they were stateless; they had to fill out documents (birth certificate, citizenship certificate etc) and go through a series of stages to obtain a passport. I also participated in this experiment. I found out that 46 was a symbolic number, representing almost 4.6 million stateless children in the world. I asked Ralph Ya, why the passport? 'Well, do you know a better way to free them from their situation of statelessness?' 85 I did not reply, but I was thinking: if there is no other way to free Neha this limbo, then this art experiment would not give a solution that has not already been considered by academics and policymakers. Regardless, it was rather a different way to show the situation and convey the message.

82 See, eg, Institute on Statelessness and Inclusion (n 27); Laura Van Waas and Melanie J Khanna (eds), Solving Statelessness (Wolf Legal 2017); Chikera and Whiteman (n 31).

83 Informal conversation with David Cottrrell, Co-founder, Empathy and Risk (Mizanur Rahman, Empathy and Risk, 24 June 2019).

84 Informal conversation with Ralph Ya, Artist, Empathy and Risk (Mizanur Rahman, 24 June 2019).

85 Informal conversation with Ralph Ya, Artist, Empathy and Risk (Mizanur Rahman, 26 June 2019). 


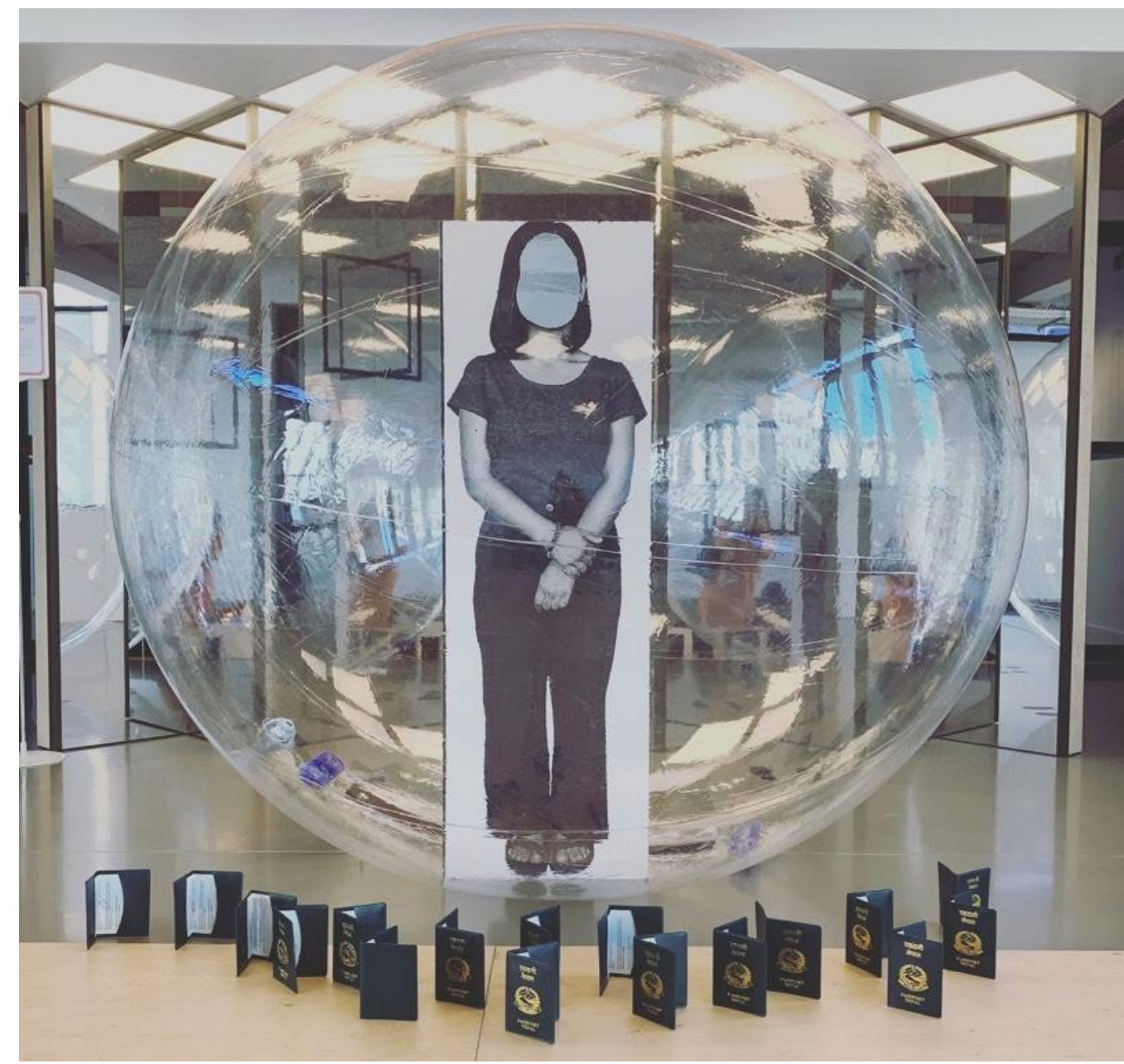

Figure 2: Neha, a stateless girl trapped inside a bubble. ${ }^{86}$

In the first stage of obtaining a passport, I had to fill a document entitled 'Prove That You Were Born, Even if You are Alive and a Breathing Human Being'. The sarcastic tone of the title seemed like a challenge to the discretion the nation-state has in deciding if you were born. It challenges the notion that a birth certificate is needed when, in reality, you exist as a human. I found this piece quite interesting. At the end of the 'birth certificate' in Figure 3 it was written:

Please present this fully accomplished form as evidence that you are not stateless. Nothing is more important than a piece of paper as compared to your live presence and actual existence, right?

These lines remain a critical reflection of the importance of state-sanctioned documents.

It took me the entire three day conference to go through all stages needed to get a 'passport'. Sometimes, the officer played by the person in the passport office was not there. Sometimes, the officer would not want to do the work. Sometimes the photo I submitted was deemed inappropriate and I was asked to resubmit it. Throughout the procedure I felt a sense of rejection and betrayal, regardless of my

86 Mizanur Rahman, Neha, A Stateless Girl Trapped inside a Bubble (Photo, World Conference on Statelessness and Inclusion, 26-28 June 2019). 
knowledge that these steps were part of the experiment. The passport officer, played by an activist associated with Empathy and Risk named Deepti from Nepal, explained it to me:

We just wanted to show you a glimpse of what it feels like to be a stateless person, knocking relentlessly on the door of the authority. It can take year after year; generation after generation. In Nepal, stateless people face all of this harassment. ${ }^{87}$

I felt emotionally distressed listening to her, thinking of the reality of actual stateless persons or groups. I promised myself then that I would dedicate myself to the field of statelessness in my future career endeavours. Finally, she gave me a passport and requested I put the passport in front of the bubble. I went there and saw only 15 passports including my own. I wondered: what was happening? Was it that people were not interested enough? In a discussion with Ralph Ya during a coffee break, I asked him, 'why were there only 15 passports?' He laughed and informed me that he had given the initial form to more than 150 participants personally, but most of them got annoyed with the process. I realised this is how the artist wanted people to have the experience of frustration. They could not take three days, so how then do stateless persons go through such experiences year after year?

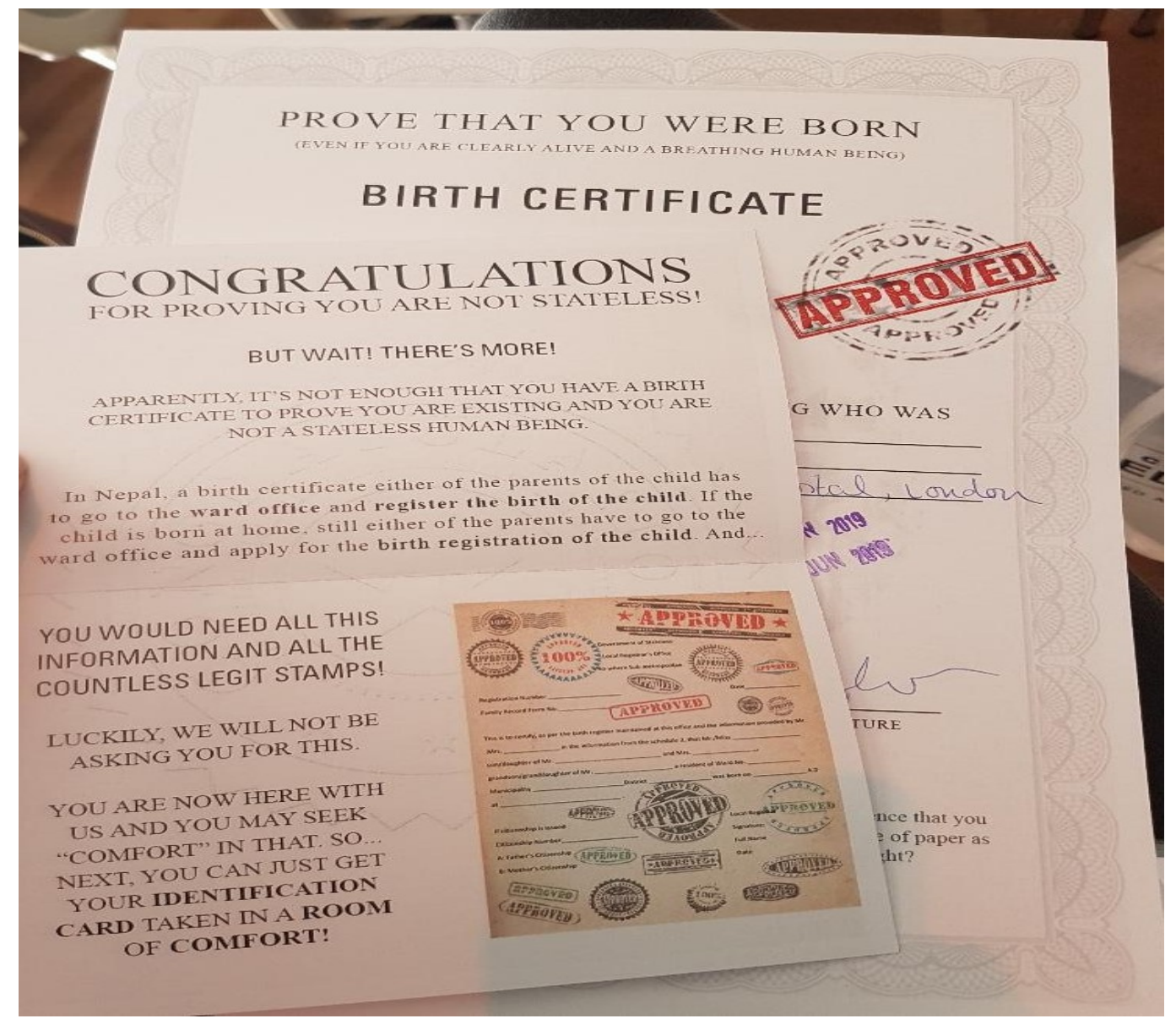

Figure 3: Write your birth certificate and prove that you were born. ${ }^{88}$

87 Informal conversation with Deepti, activist (Mizanur Rahman, Empathy and Risk 28 June 2019).

88 Mizanur Rahman, Write Your Birth Certificate and Prove That You Were Born (Photo, World Conference on Statelessness and Inclusion, 26-28 June 2019). 
On the third day morning, Ralph Ya made another announcement: 'Dear Participants, we still need 30 passports to free Neha, please cooperate'. Ralph asked me to go to participants and motivate them to go through the process, which I did. I remember two of the participants telling me that they tried to get the passport but the process was too long and they got distracted. I told them that was because the experiment wants to show people how devastating and dehumanising the process was, they listened to me and hugged me. One of them said, 'you are right, sorry, I did not think that way, I am going to get it now' ${ }^{89}$ By 5:00 PM Ralph declared that they had received 46 passports and it was time to free Neha. There were a lot of people in front of the bubble, taking pictures and talking. Ralph Ya placed himself in front of the bubble, looking very happy. He thanked all of the participants who went through the whole process. After that, he lifted the bubble from the symbolic Neha. Everyone clapped and cheered. The person standing near me was telling another participant,

this is nice, but it is also over-ambitious. If the state does not want to give them the passport no way you can lift the bubble around them, which is the case now and I am not sure if it will change. ${ }^{90}$

Another person replied,

it's a shame that they are living in a bubble their whole life, I see her as a living embodiment of every stateless child and imagining my children in such a bubble is very frightening. ${ }^{91}$

I looked at the persons face and I saw sadness. In my opinion, this feeling of empathy that arose from the participants was the main objective of this art experiment.

Empathy has been generally described in literature as a 'capacity' to feel and realise others' state of mind and emotions. More generally it has been characterised as 'putting oneself into others' shoes' ${ }^{92}$ Empathy has been widely recognised and used by feminist scholars to build affective solidarity, to facilitate political transformation, to challenge the objectivity of knowledge and to promote a different way of knowing things. For instance, Claire Hemmings states,

to know differently we have to feel differently. Feeling that something is amiss in how one is recognised, feeling an ill fit with social descriptions, feeling undervalued, feeling that same sense in considering others... . ${ }^{93}$

One of the major advocates of the feminist intersectionality approach, Patricia Hill Collins states,

89 Conversation with an anonymous participant (Mizanur Rahman, World Conference on Statelessness and Inclusion, 28 June 2019).

90 Observation note, reaction of an anonymous participant ((Mizanur Rahman, World Conference on Statelessness and Inclusion, 28 June 2019).

91 ibid

92 See, eg, Cynthia V Ward, 'A Kinder, Gentler Liberalism? Visions of Empathy in Feminist and Communitarian Literature' (1994) 61(3) University of Chicago Law Review 929; F Ioannidou and Vaya Konstantikaki, 'Empathy and Emotional Intelligence: What is it Really About?' (2008) 1(3) International Journal of Caring Sciences 118; Alison Bailey, 'On Intersectionality, Empathy, and Feminist Solidarity: A Reply to Naomi Zack' (2009) 18(2) The Journal of Peace and Justice Studies 14; Claire Hemmings, 'Affective solidarity: Feminist reflexivity and political transformation’ (2012) 13 Feminist Theory 147.

93 Claire Hemmings (n 68) 150. 
the ability to empathise is not only important for a feminist subject committed to knowing differently but may also be a condition of being understood as trustworthy by those within marginal communities used to being mis-represented. ${ }^{94}$

From my experience and observation, I felt 'Freeing Neha' succeeded in creating empathy for the stateless by showing what it was like to be trapped in 'legal limbo'. It was also critical to the state and questioned the legal process in different ways. However, the solution it offered was centred on the state and obtaining passports.

So, on the one hand, it certainly humanised the condition of statelessness and provoked radical empathy, but on the other, it does not challenge the state-centred discourses related to statelessness. Rather, it showed that the solution to statelessness is still located within the nation-state framework and thus, does not offer any different path from the legal approach - an emphasis on obtaining passports as the fundamental means of Neha's freedom from a 'legal limbo'.

\section{B Unseen and Untouchables: Searching for Hope with Hope}

Statelessness is often portrayed as a grim situation for stateless people. For example, Marion Couldrey and Maurice Herson entitled one of their works on statelessness as 'No Legal Identity, Few Rights, Hidden from Society, Forgotten'. ${ }^{95}$ This title draws a picture of stateless people and groups who are in total despair, drowning in an ocean of sorrow and uncertainty. Literature on statelessness has a tendency to talk about stateless people as if they are an embodiment of passiveness; they do not possess any hope, they do not have any agency, they cannot resist and as if they are only a category, a term or variable. They are only defined by their legal status; their nationality and citizenship. In an informal conversation, David Cotterell addressed this framing of stateless people: 'There is a problem in the conceptualisation of stateless people. They are stateless, but still, they are human beings, they have hope, they have family, they get angry too, we need to recognise those'. ${ }^{96}$ In my observation notes 'hope' and 'agency' featured on many occasions. Both Creative Court and Empathy and Risk think statelessness can be truly humanised through art that shows these fundamental sides of human beings. In line with the previous Part, the following paragraphs show how art and art interventions intend to represent hope and agency and, thus, humanise the condition of statelessness. I also critically observed the following artworks and practices to understand the type of knowledge they produce and how they are constructed.

'There is not a single human being in this world who has no hope, everyone possesses some kind of hope', says Manish Harijan, a Nepalese photographer and artist for Empathy and Risk. Manish installed some of his photography to represent the situation of stateless people and performed a live performance entitled 'Unseen and Untouchable'. I had several opportunities to meet with Manish. He explained to me how his ideas on statelessness are closely related to his personal experiences. His initial photographs were inspired by his personal experience of being

94 Claire Hemmings (n 69) 151, citing Patricia Hill Collins, Black Feminist Thought: Knowledge, Consciousness, and the Politics of Empowerment (Routledge 2000).

95 See generally Marion Couldrey and Maurice Herson (eds) [2009] 32 Forced Migration Review.

96 Informal conversation with David Cottrrell, Co-founder, Empathy and Risk (Mizanur Rahman, Empathy and Risk, 29 June 2019). 
threatened and oppressed as an artist and member of the Harijan ('untouchable') community that paints Hindu deities collaborating with western superheroes. His work was not accepted for exhibition in Kathmandu. When he had the opportunity to present his work on statelessness, he found his experience was quite similar to stateless people. He said, 'I found myself as unseen and untouchable in my society and my situation is quite similar to the stateless person, who exist in reality, yet they are invisible'. 97

I was impressed by how he had translated his personal experience to conceptualise the situation of stateless people. I asked him 'why, then, do you intend to represent your artwork in a conference on statelessness? Your artwork derived primarily from your own experience, what do these artworks and experiments have to do with statelessness?' He replied,

My experience taught me that the ultimate vulnerabilities come from nonrecognition. When people are overlooked and ignored on the basis of religion, caste, class, gender, ethnicity and nationality nothing could be worse. Statelessness is the same situation of non-recognition, it is the ultimate non-recognition. People or groups just do not belong anywhere, thus they become unseen, they become untouchable, and they become ghosts. But they are human, they have hope and need hope..$^{98}$

I could not have agreed more.

On 26 June 2019, the first day of the conference, Creative Court and Empathy and Risk scheduled Manish's live performance during lunchtime. Manish sat on a chair in front of a table wearing a huge bowl (made of steel) on his face. He was moving his head very slowly, his hands were also moving around the table very slowly like he was searching for something. I saw almost everyone was looking at him. One of the participants brought food for him and placed the food in front of him. The participant also sat in front of him, he asked Manish, 'what do you need? I brought you food, you can eat'. But Manish remained silent and kept moving his hands around the table. The person looked disconcerted and said, 'I am not sure what you want'. ${ }^{99}$ The second person came and sat in front of him. She was talking to him, at one moment she touched the moving hands of Manish and I saw his hands firmly take the participant's (Figure 4). I was standing close to them. She then declared enthusiastically, 'I get it, we need to give them a hand, so that they do not feel abandoned'. ${ }^{100}$ Later, I also did the same, and he repeated his act as earlier; as soon as my hand reached his, he held firmly. I felt that the goal of these live performances was to create empathy for stateless persons, who you do not see, cannot talk to, but need assistance regardless - they need humanity to step up for their cause. They are searching for hope, even though the system makes it quite impossible for them. Later I asked him, why did you hold hands and do nothing else? He replied, 'holding hands symbolises that they are searching for hope and ways to end their stateless situation, maybe those hands were providing some hope'. 101

97 Informal conversation with Manish Harijan, artist (Mizuran Rahman, 22 June 2019)

98 ibid.

99 Reaction of an anonymous participant (Mizanur Rahman, World Conference on Statelessness and Inclusion, 26 June 2019)

100 Reaction of an anonymous participant (Mizanur Rahman, World Conference on Statelessness and Inclusion, 26 June 2019)

101 Informal conversation with Manish Harijan, artist (Mizanur Rahman, 26 June 2019) 


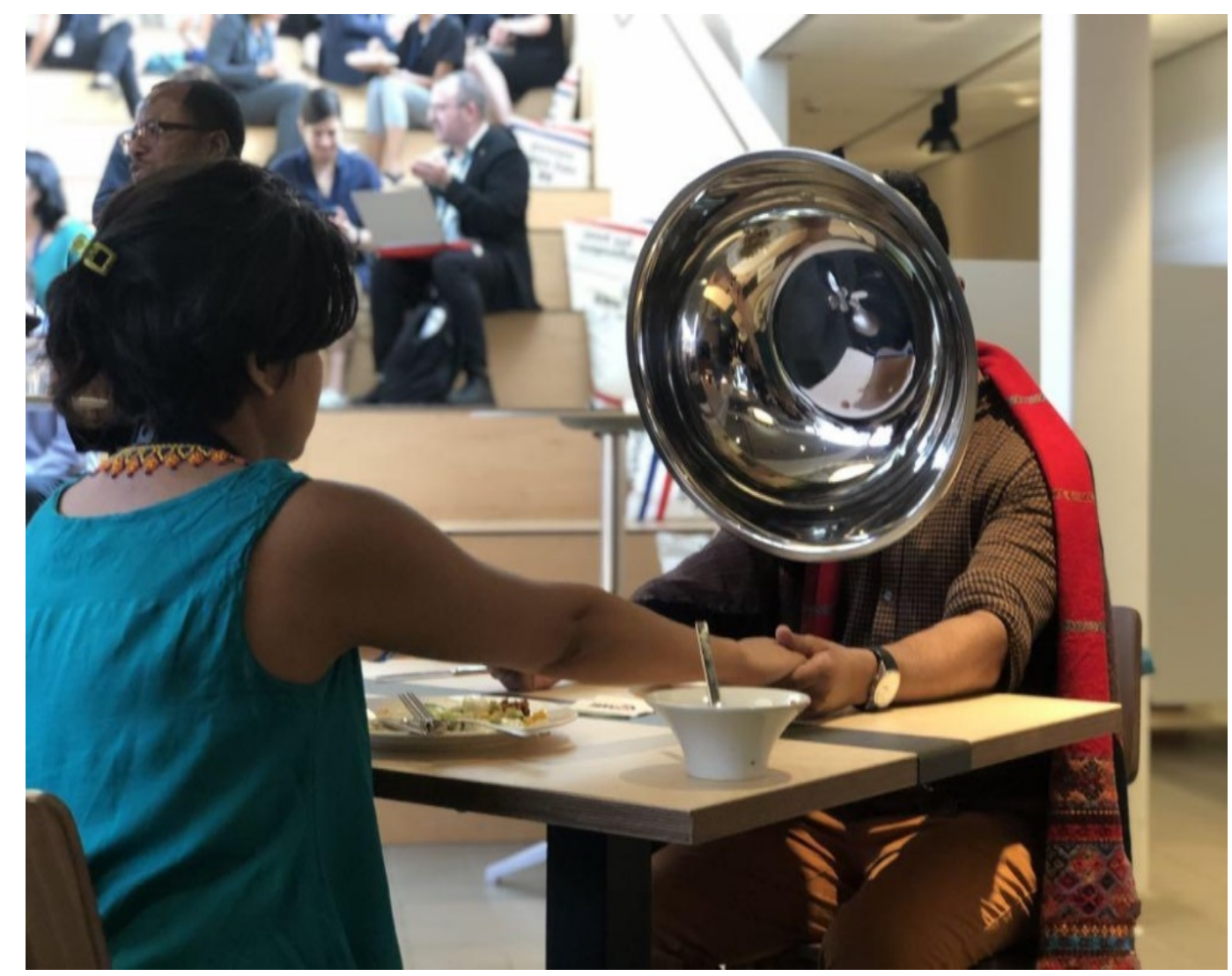

Figure 4: Searching for hope. ${ }^{102}$

In contrast to representing stateless people as frustrated, disappointed or as those with 'bare lives', the art experiment employed by the organisations emphasised one of the most basic human aspects - hope. 'Hope itself is an interesting concept and political idea. Without it there is despair and a sense of futility'. ${ }^{103}$ For centuries, hope has been featured as a central theme in artistic, philosophical and religious endeavours and explanations. ${ }^{104}$ More recently, especially in the feminist school of thought, hope became a central theme. Rebecca Coleman and Debra Ferreday argue, ' $[\mathrm{h}]$ ope is central to marginal politics which speaks of the desires for equality or simply for a better life'. ${ }^{105}$ A leading theorist on hope defined it as something that, 'sustains life in the face of despair' and 'the drive or energy that embeds us in the world - in the ecology of life, ethics and politics'. ${ }^{106}$ The live performance of Manish shows hope - which values life and human aspiration over the unimaginable difficulties stateless people are facing because:

102 Mizanur Rahman, Searching for Hope (Photo, World Conference on Statelessness and Inclusion, 26-28 June 2019).

103 Chris Barker, Brian Martin and Mary Zournazi, 'Emotional Self-Management for Activists' (2008) 9(4) Reflexive Practice 423, 430.

104 Nauja Kleist and Stef Jansen, 'Introduction: Hope over Time - Crisis, Immobility and Future-Making' (2016) 27(4) History and Anthropology 373.

105 Rebecca Coleman and Debra Ferreday, 'Introduction: Hope and Feminist Theory' (2010) 14(4) Journal for Cultural Research 313.

106 Marry Zournazi, Hope: New Philosophies for Change (Pluto Press 2003) 14, 14-15. 
It is a basic human condition that involves belief and trust in the world. It is the stuff of our dreams and desires, our ideas of freedom and justice and how we might conceive life. 107

In the conference, this particular art experiment tried to evoke a hope that does not ignore the suffering of others; a positive hope that stateless people hold as humans, which further succeeds in humanising the issue of statelessness.

In my opinion, however, it is worth noting that this conceptual art experiment - of presenting the hope of stateless people — did not come directly from the stateless persons themselves. As a result, we cannot know for sure if stateless persons themselves would conceptualise it in the same way or how they would have preferred to present it artistically. Rather, it is based on the very subjective experiences of the artist; the combination of his experience and the dominant narratives of statelessness (invisibility and of a people drowned in despair). In short, it is not informed or translated from the experiences of stateless persons and remains a top-down interpretation of stateless people's experiences and trajectories.

\section{How Do You Survive in a World That Does Not Recognise You?:}

\section{Recognising 'Agency'}

It is commonly agreed that statelessness is a status of victimhood where stateless persons are passive victims of circumstance. ${ }^{108}$ Creative Court has been working on their new project to show the agency and resilience of stateless people, instead of looking at them as 'passive victims'. The last two months of my internship were solely focused on Creative Court's statelessness project. I was often engaged in discussion with Rabiaa and participated in six concept development meetings alongside the other members of Creative Court. During the first concept development meeting, Rabiaa declared that her idea was to focus on the perceptions and activities through which stateless persons connect themselves with a world that does not recognise them, then translate it using an artistic medium to visualise it. ${ }^{109}$ She also told me her initial idea was not to focus on stateless people's vulnerabilities and sufferings, rather their agency and practices. ${ }^{110}$ She was interested and invested in the situation of Western Sahrawi, where a group of stateless persons currently live in an occupied territory of the Moroccan desert. Rabiaa gave me an interview to transcribe, one which she conducted with a stateless person from Western Sahrawi, Drik. ${ }^{111}$

In the interview, Drik shed light on the many aspects of their stateless life. Drik expressed a strong sense of identity regarding the Western Sahrawi community. According to him, Sahrawi culture is about the words, stories, poetry and advice of their wise men, they pass it down through generations. They are nomadic, constantly searching for water. He emphasised that even though they are living in a camp, in the middle of a desert, under an occupied territory, frozen in a status quo, they remain survivors. He said, 'we are not stateless, the oppressors made us.

107 ibid 12.

108 See Bloom, Tonkiss and Cole, 'Introduction' (n 27) 3.

109 Concept development meeting with Rabiaa Benlahbib, Director, Creative Court (Mizanur Rahman, Creative Court 12 July 2019).

110 ibid

111 In order to protect the person's identity, I am using a pseudonym. 
We suffered a lot, but we exist, they cannot take it away from us'. ${ }^{112}$ Drik also strongly believes in Sahrawi identity, and stated that while they do not have much, they care strongly about who they are. He also mentioned that they protect their identity despite all the suffering. Some of them applied for Moroccan Nationality for money and comfort, but the majority would not accept them back into the community; the community would not think that they are Sahrawi anymore. ${ }^{113}$ As I was listening to the interview, I felt a pain for Drik and his people. I immediately thought of over a million stateless Rohingya refugee people who reside in my country because their identity was stripped away as they suffered persecution in their country of origin, Myanmar. However, towards the end of the interview, Rabiaa asked Drik if he could connect the Sahrawi people with the plant world. Drik took some time and then suggested that they are like cacti. They survive in a desert with barely any resources. 114

After the interview I worked with Rabiaa to translate Drik's perception and conception of the Western Sahrawi community. She wanted to visually interpret the concepts therein through the plant metaphor. We discussed whether the cacti could represent the Western Sahrawi community and Drik's idea of identity, agency and survival.115 I researched cacti and after reading about their characteristics I was also convinced that the situation Drik described could be interpreted as such. Found in deserts, cacti can survive in extremely difficult environments; to survive they have adapted by adopting distinctive physical and behavioural mechanisms. Cacti are drought resistant, do not have any leaves which reduces transpiration (loss of water in the air), they can store water in their long roots from a single period of rainfall and can use it for years. ${ }^{116}$ Rabiaa also informed me that there are also specific types of desert cacti that can move through the desert. ${ }^{117}$ Hence, Creative Court decided to use cacti as a metaphor to visualise and translate agency and represent the resilient nature of Western Sahrawi stateless people (Figure 5).

112 Interview with Drik (Rabiaa Benlahbib, transcribed 20 July 2019).

113 ibid.

114 ibid.

115 Concept development meeting with Rabiaa Benlahbib, Director, Creative Court (Mizanur Rahman, Creative Court 22 July 2019).

116 For details, see Ravikiran Kulloli and Suresh Kumar, 'Conservation of Cacti in the Desert Botanical Garden, Jodhpur, India' (2017) 8(2) International Journal of Environmental Science 172, 179.

117 Concept development meeting with Rabiaa Benlahbib, Director, Creative Court (Mizanur Rahman, Creative Court 25 July 2019). 


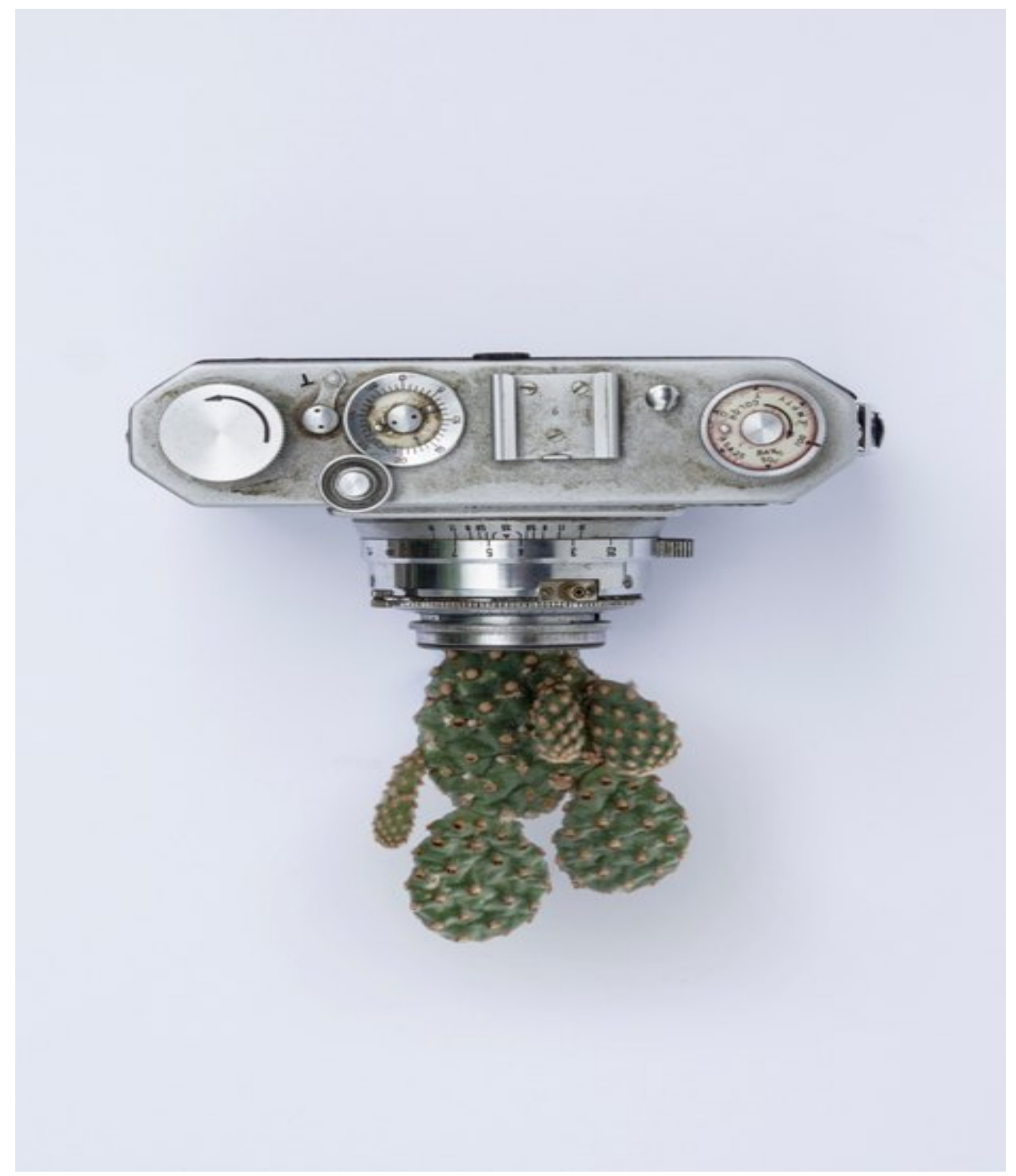

Figure 5: Visualising stateless people as cacti. ${ }^{118}$

The Creative Court intended to bring out the issue of agency. Agency is defined by Gell as something

attributable to those persons (and things ...) who/which are seen as initiating casual sequences of a particular type, that is, events caused by acts of mind or will or intention ... independently of the state of the physical universe'. ${ }^{119}$ Anthony Giddens defined agency as people's ability to act in a certain way where multiple courses of action are possible. ${ }^{120}$

\footnotetext{
118 'How to Recognise a Tree', Creative Court (Web Page) $<$ https://www.creativecourt.org/index.php/portfolio/work-in-progress/>.

119 Gell (n 23) 16.

120 Robert Layton, 'Art and Agency: A Reassessment' (2003) 9(3) Journal of the Royal Anthropological Institute 447, 451.
} 
For Giddens, constraints enable people to exercise their agency. ${ }^{121}$ The interview with Drik suggests that the stateless people of Western Sahrawi do not see themselves as stateless, and most of them do not have any intention of accepting Moroccan citizenship despite their suffering. The will to resist against the condition, to survive and to protect their identity, clearly shows the agency of the Western Sahrawi people - qualities that Drik himself thinks emulate cacti.

Contending with Deirdre Brennan, ${ }^{122}$ I came to realise that these theories on agency can play a significant role in understanding the concepts of definition and self-identification. By asking questions such as "what are the implications of portraying stateless people as the victims? Invisible? Legal ghosts? People of nowhere?' 'In what circumstances do people want to be defined as stateless people?' Or, 'in what space can stateless people be seen as having and practising agency?' 123 Similarly, universally portraying stateless people as 'victims', 'nowhere people', 'submissive', 'people with bare lives' and waiting for 'citizenship' ignores their complicated and contextual history, identity and culture. Through the use of an artistic approach, Creative Court intended to go beyond these portrayals and wanted to represent the agency of the Western Sahrawi stateless people by portraying them as cacti; strong, resilient and able to survive in harsh environments.

Despite their intention, the 'agency' perspective adopted by Creative Court suffers similar limitations to that of 'hope', where there is a clear absence of first hand stateless perspectives on artworks. Creative Court's agency argument, and their act of showing stateless people as a resilient and aware group of survivors, is based in a single chance encounter with a stateless person. The photographs and artworks presenting such agency were not developed with stateless people, their concern and consent were not counted in the process. So, the question can be asked, who represented whom and how? Creative Court's ideas and knowledge did not arise from empirical research with the Western Sahrawi population residing inside the Moroccan territory. Again, it was a different way of seeing and imagining, but it followed the same path of totalising the experience of the Western Sahrawi stateless population, based on the view of one particular member of the community. This is a nice idea to show the agency of stateless people and recognise their existence, but it lacks empirical grounds. With all the concerns regarding the humanisation of statelessness, when Creative Court sees stateless people through plant metaphors, in a way, they also dehumanise stateless people - their experiences become objectified when translated into plants or artworks. This is a paradox created by the organisation.

\section{CONCLUSION}

Throughout this article, I have analysed an art-based approach towards statelessness to show how it is different from the currently dominant frameworks. These dominant discourses on statelessness emphasise a lack of legal bond between the state and the individual. The personal experiences and perceptions of stateless people are mostly invisible in such discourses. Stateless persons are perceived as 'legal ghosts', as if they do not exist, and as vulnerable and passive

121 Anthony Giddens, The Constitution of Society (Polity Press 1984) 173.

122 Deirdre Brennan, 'Statelessness and the Feminist Toolbox: Another Man Made Problem with a Feminist Solution?’ (2019) 24(2) Tilburg Law Review 170.

123 See ibid 172. 
victims. This dominant framing dehumanises stateless people. Art-based approaches propose to set out different narratives and discourses of statelessness, focusing on the human aspects of being stateless to humanise the issue. Creative Court and its partner intended to bring forward the vulnerabilities, hope and agency of stateless people, as well as subtly question current understandings. This art-based approach intended to present alternative perspectives on statelessness. It framed statelessness as a 'human' issue', rather a mere 'legal' issue. I demonstrated, through my analysis, that the artistic approach recognises basic human aspects concerning stateless people and goes beyond how statelessness is dominantly framed and represented. This reflects Creative Court and Empathy and Risk's principal objective of framing and representing statelessness in a humanising way, so that other people can connect themselves to stateless persons through empathy. I felt the art-based approach succeeds in doing so. However, careful analysis of these artworks shows that even if the framing of statelessness is humanised, the solution often remains a legal one, lacking a view of stateless people themselves. Nevertheless, this artistic approach can be seen as an effort to study statelessness from a different angle that shows human aspects of the stateless situation.

Finally, I want to address three issues that are worthy of further exploration. First, I both felt and observed that the conference artworks succeeded in generating in the participants, including myself, an empathy towards stateless people. However, I am not sure how these artworks would have been received by a different audience who did not necessarily possess an interest in, or knowledge of, the issue of statelessness. The conference itself was about statelessness, participants were invited selectively based on their expertise or engagement in the issue. Therefore, I felt it was relatively easy to generate such empathy in participants that were already invested in statelessness in some way. What would have happened in a different location or setting, with people who are not generally aware of, or concentrated on, statelessness? It would be interesting to gauge the responses of more general audiences. Second, the artworks I have observed were not community-led artworks. While the artists and the organisations met with some stateless people, collected their stories and translated them into artworks, we do not know if the stateless persons themselves would represent their stories, hope, agency, identity and resilience in the same manner. How would they have done it? Future researchers could think about engaging themselves in a community-led art project to see the difference. Third, there is a growing concern regarding 'the ethnographic turn in art'. ${ }^{124}$ Statelessness is a very complex issue; stateless persons and groups experience statelessness in different ways and in different socio-cultural, economic and political contexts. It would be interesting to combine ethnographic knowledge in art-based approaches to grasp these perceptions, practices and meanings of statelessness. Thus, I believe an ethnographic turn in art practices regarding statelessness can further enhance the cause of humanising statelessness. Community-led art projects, and the utilisation of ethnographic knowledge to translate them into artistic representations of statelessness, could generate radical empathy for the stateless people. In turn, this could influence

124 See, eg, Anna Grimshaw and Amanda Ravetz, 'The Ethnographic Turn - and After: A Critical Approach towards the Realignment of Art and Anthropology' (2015) 23(4) Social Anthropology 428; Kris Rutten, An van Dienderen and Ronald Soetaert, 'Revisiting the Ethnographic Turn in Contemporary Art' (2013) 27(5) Critical Arts 459 $<$ https://www.tandfonline.com/doi/abs/10.1080/02560046.2013.855513>. 
policymakers to see this issue not only from a legal and political position, but also from a humanist one. This was, and is, one of the main objectives of Creative Court and Empathy and Risk. 